International Journal of Pure and Applied Mathematics

Volume 105 No. 3 2015, 451-457

ISSN: 1311-8080 (printed version); ISSN: 1314-3395 (on-line version)

url: http://www.ijpam.eu

doi: http://dx.doi.org/10.12732/ijpam.v105i3.13

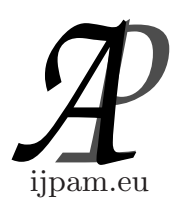

\title{
GRAPH MODELS OF SOCIAL MOBILITY ON THE BACKGROUND OF STRATIFICATION
}

\author{
Nasim Rustamov $^{1 \S}$, Nurbai Dosanov ${ }^{2}$, Yunusbek Rustamov ${ }^{3}$ \\ ${ }^{1,2}$ A. Yasawi International Kazakh-Turkish University \\ Turkestan, KAZAKHSTAN \\ ${ }^{3}$ Tashkent Regional Criminal Court \\ UZBEKISTAN
}

\begin{abstract}
The work is devoted to creating a mathematical model of social mobility society. Since social mobility defines the structure of society, with the help of this model, it will be possible to predict the dynamics of the society. This simulation is carried out with the help of graph theory, enabling visually analyze the essence of the process of stratification. Stratification is an expression of the law of the unity of contradictions and the moving force development or destruction of society. It was shown that the stratification is a model socially and mobility of society.
\end{abstract}

Key Words: social mobility, stratification, graph model, mobility, assessment of social mobility, the structure of socium

\section{Introduction}

Human activities in some degree always are designed. But some natural processes and phenomena are useful to think as if they are artificial, designed to achieve a certain goal. This technique is widespread in science. It was such a treat stratification process modeling that cause constructive or destructive phenomena in socium $[1,2]$.

Received: September 25, 2015

(C) 2015 Academic Publications, Ltd.

$\S$ Correspondence author url: www.acadpubl.eu 
Inequality distances between statuses are basic property stratification. Stratification process can be characterized as a mechanism for the development, or the mechanism of destruction of society due to social mobility. From this point of view the interest of this modeling process has recently grown up. First of all, this is due to the need to manage, predict the processes taking place within society.

Open and closed systems of stratification are distinguished. Social structure, members which can change their status is relatively easy, open system called stratification. Structure, members who can change his status with great difficulty, called a closed system of stratification. Several similar differences are reflected in the concepts of progress and prescribed status: achieved status acquires on individual choice and competitive struggle, while prescribed statuses were given to group or society. This process will be the starting point for the beginning of social mobility, which is the cause of the beginning of the process of social stratification.

In open systems of stratification every member of society can change their status, climb or descend the social ladder through their own efforts and abilities. Modern society experiencing the need for qualified and competent professionals who can manage the complex social, political and economic processes provide enough free movement of individuals in the system of stratification. This is the basis of social mobility [3]. The consequences of such movements between Member socium striation, will be the beginning of a new stratification in the same society. Therefore, the process of stratification occurs on social mobility has always occurred on the background stratification.

The purpose of the work: To create against the background of stratification of a graph model to assess the social mobility of society.

\section{The Method of Solution}

As you know, social stratification - a differentiation of some given set of people (population) into classes in a hierarchical rank. It finds expression in the existence of higher and lower layers. Its foundation and essence in the uneven distribution of rights and privileges, responsibilities and duties, the presence and absence of social values, power and influence among the members of a community [3].

At its core, the process of stratification is a model of social mobility. This process can be assessed by determining direction stratification. In this case, the society is represented as a graph on this graph stands out strongly connected 
vertices [4]. Strongly related peaks reflect stratum of society. The numbers of incoming and outgoing vertices express social mobility society. Mobility for hidden structural changes in society. On the basis of this concept, we can estimate the criterion of social mobility, giving impetus to the processes of stratification in society. In this case social mobility is expressed on the background stratification [5]. If it so you can create a graph model of social mobility by the method proposed in $[6,7]$. To do this, we introduce the following additional concepts.

Definition 1. The graph $G(E, \Gamma)$ is called strongly connected, if

$$
\left(\forall X_{i} \in E\right) \hat{\Gamma} X_{i}=E
$$

i.e for any two vertices $X_{i}, X_{j}$ in this graph there is a path leading from $X_{i}, X_{j}$ (Figure 1.).

Definition 2. If $C\left(X_{i}\right)$ - the class containing ${ }_{i}$, then

$$
C\left(X_{i}\right)=\hat{\Gamma} X_{i} \cap \hat{\Gamma}^{-} X_{i}
$$

Expansion will count on maximal strongly connected sub graphs (Figure 2). It is clear these sub graphs are striation of socium.

Algorithmic model is as follows. We take derivative the top of $X_{i}$ and find $\hat{\Gamma} X_{i}, \hat{\Gamma}^{-} X_{i}$ and $\hat{\Gamma} X_{i} \cap \hat{\Gamma}^{-} X_{i}$. Then we take vertex $X_{j} \notin C\left(X_{i}\right)$ and act similarly.

We continue the process as long as possible.

Thus, formula (2) is an algorithmic model of the process of stratification. The graph model of social mobility is created using certain functions ordinal graph without contours.

\section{Ordinal Function of Graphs Without Contours}

We consider graph without contours $G(E, \Gamma)$ and define the subset

$$
\begin{gathered}
\left(N_{0}, N_{1}, \ldots, N_{\mathrm{r}}\right): \\
N_{0}=\left\{\mathrm{x}_{i} \mid x_{i} \in E, \Gamma^{-1} x_{\mathrm{i}}=\right\} \\
N_{1}=\left\{\mathrm{x}_{\mathrm{i}} \mid \mathrm{x}_{\mathrm{i}} \in \mathrm{E}-\mathrm{N}_{0}, \Gamma^{-1} x_{\mathrm{i}} \subset N_{0}\right\} \\
N_{2}=\left\{\mathrm{x}_{\mathrm{i}} \mid \mathrm{x}_{\mathrm{i}} \in \mathrm{E}-\left(\mathrm{N}_{0} \cup \mathrm{N}_{1}\right), \Gamma^{-1} x_{\mathrm{i}} \subset N_{0} \cup N_{1}\right\}
\end{gathered}
$$




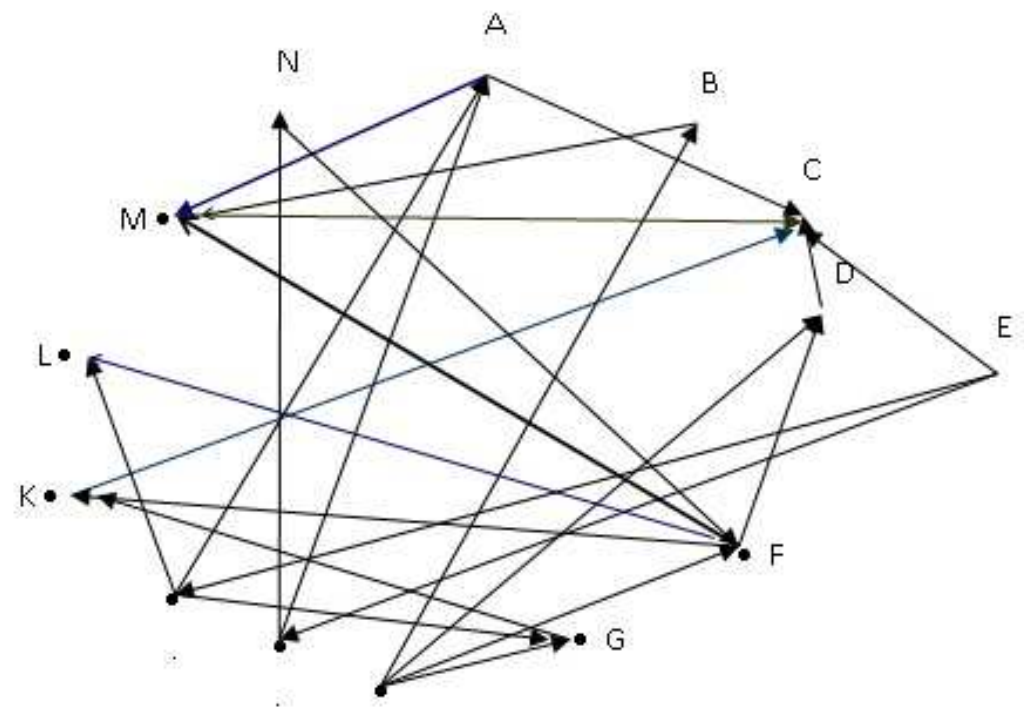

Figure 1: A graph model of socium.

$$
N_{\Gamma}=\left\{\mathrm{x}_{\mathrm{i}} \mid \mathrm{x}_{\mathrm{i}} \in \mathrm{E}-\bigcup_{\mathrm{R}=0}^{\mathrm{r}-1} N_{\mathrm{R}}, \quad \Gamma^{-1} x_{\mathrm{i}} \subset \bigcup_{\mathrm{R}=0}^{\mathrm{r}-1} N_{\mathrm{R}}\right\}
$$

where $r-$ is the smallest integer such that

$$
\Gamma N_{\Gamma}=\emptyset
$$

It is easy to show that a subset, $N_{\mathrm{R}}, R=0,1,2, r_{1}$ constitute a partition $E$ and it is quite ordered by the relation

$$
N_{\mathrm{R}} \mapsto N_{R^{I}} \Leftrightarrow R<R^{I}
$$

The function $O(X)$, defined by

$$
x_{i} \in N \Rightarrow O\left(x_{i}\right)=R
$$

It is called ordinal function graphs without contours. In other words, it is proposed to split the set of vertices of the graph without contours into disjoint subsets, ordered so that if the vertex belongs to the subset with a number of $\mathrm{R}$, then the next one vertex is included in the subset with a number greater than R. subsets of this partition is called levels. 


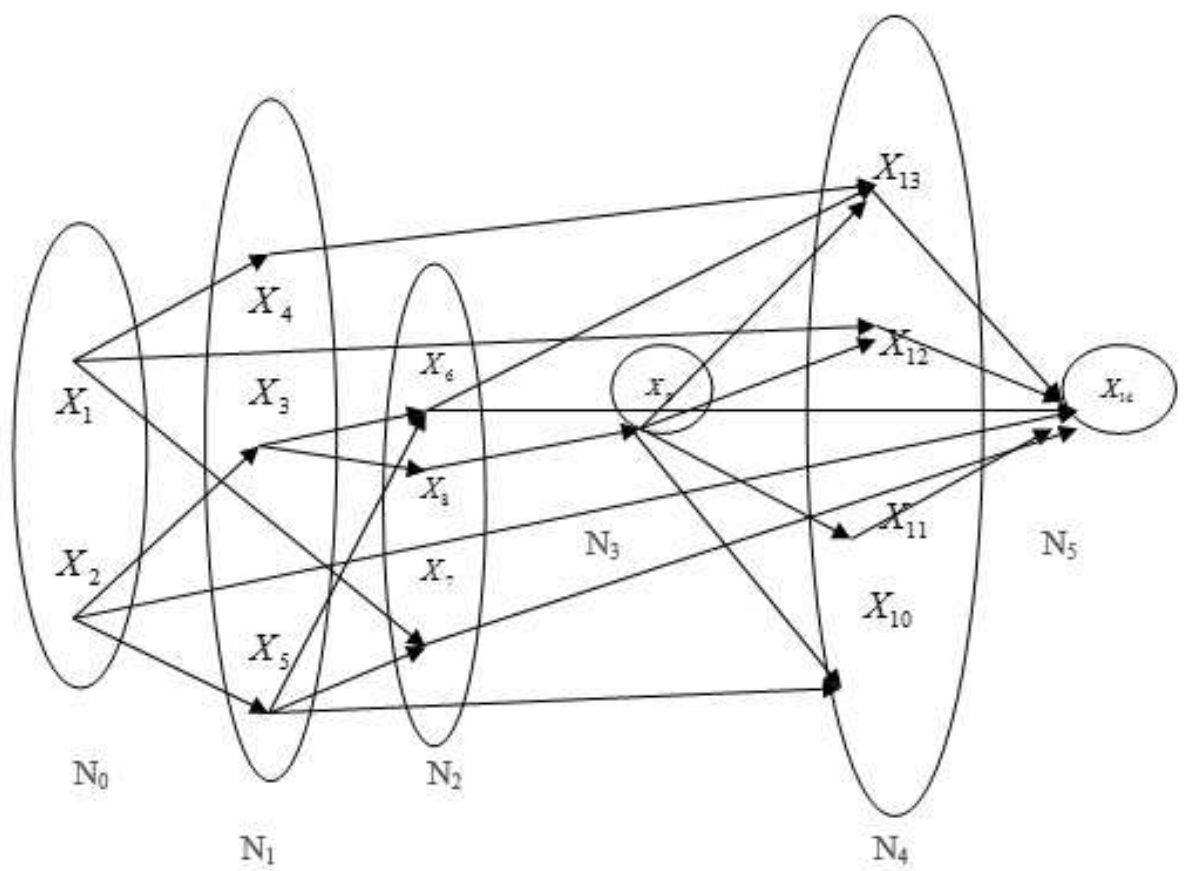

Figure 2: Background stratification of society.

Example. Assume that each striation of socium no one is denoted by the top of the graph (Figure 1), and the relationship between these striation ribs. The degree of influence is reflected in the direction of the striations of edges of the graph. Figure 2. There are shown levels which decompose the set of vertices of the graph in Figure 1. Each vertex $x_{i}$ of the graph corresponds to some $N_{\mathrm{R}}$, i.e. some $R \in\{1,2, \ldots, 5\}$. It is an ordinal function $x_{i} \mapsto R$ is given by the table.

\begin{tabular}{|l|l|l|l|l|l|l|l|l|l|l|l|l|l|l|}
\hline Vertex & $A$ & $B$ & $C$ & $\mathrm{D}$ & $E$ & $F$ & $G$ & $H$ & 1 & $J$ & $\mathrm{~K}$ & $\mathrm{~L}$ & $\mathrm{M}$ & $\mathrm{N}$ \\
\hline Level & 2 & 1 & 5 & 4 & 0 & 3 & 2 & 0 & 1 & 1 & 4 & 4 & 4 & 2 \\
\hline
\end{tabular}

Ordinal function graph without contours can be defined in various ways; as the initial set can be taken arbitrarily set of vertices containing $N_{0}$. Ordinal function allows you to renumber the vertices so that the level of vertex numbers is smaller than the vertex level $N_{i+1}$ (Figure 3). Ordinal function expresses the structure of the structure of socium. Therefore ordinal function of plays an important role in managing process of stratification.

Conclusions. It is interested in modeling of social processes is always 


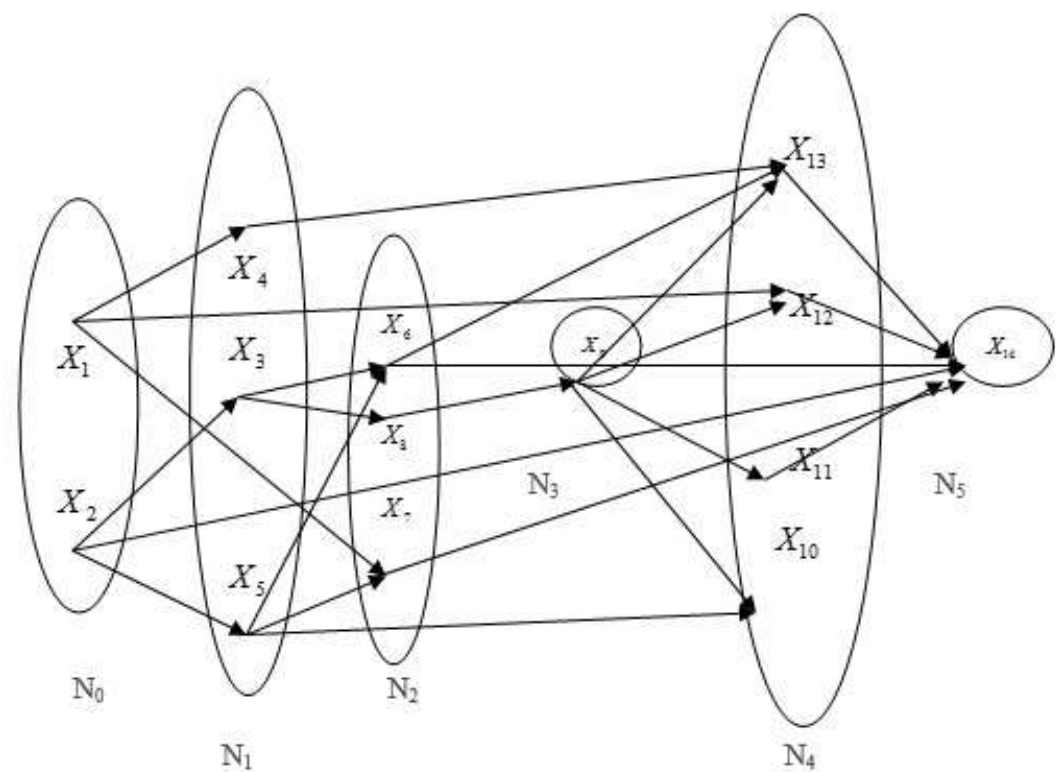

Figure 3: The graph model of social mobility.

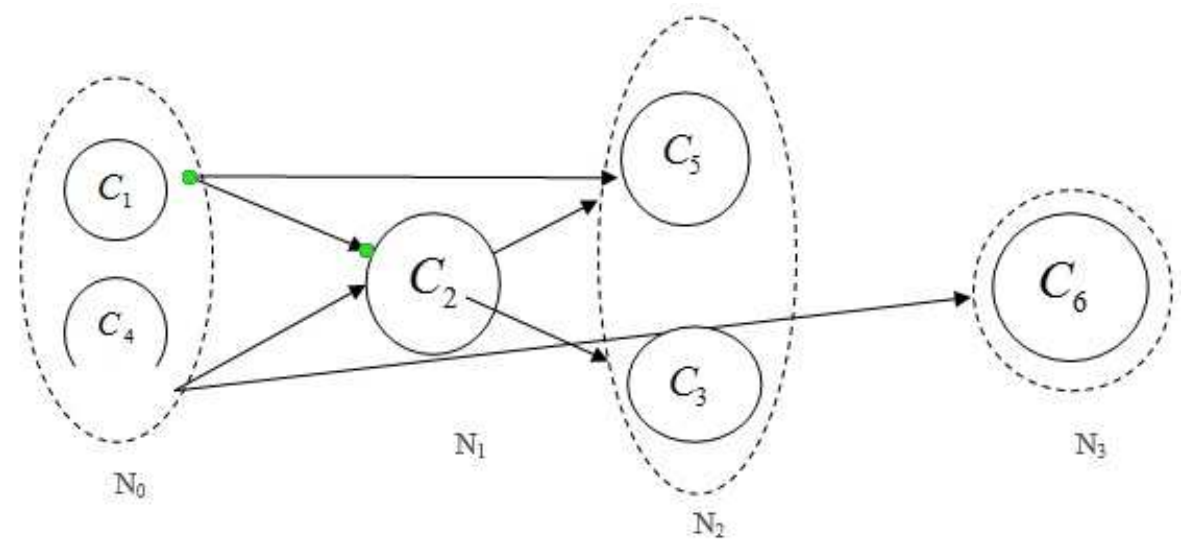

Figure 4: Social mobility in the background of stratification.

in requirement. So how to manage these processes ensures the well being of socium. One of the social stratification is processes. The social stratification is related to the concept of "social mobility". "Any transition individual or social object (value), that is all that is created or modified by human activity, from one social position to another" refers under the social mobility. 
Social structure is a qualitative definition of society, so it expresses a radical change in the qualitative shift in society mathematical model of social mobility based on the graph theory verbally expresses the essence of the process of social mobility.

\section{References}

[1] N.T.Rustamov, Yu.K.Rustamov, Impact of social stratification to phenomenon of "terrorism" - materials of international conference "Counter terrorism and Human security", Zurich, (2013), 1898-1902.

[2] N.T.Rustamov, Yu.K.Rustamov, J. Anarbayev, Information-logical model of phenomenon "terrorism", 5th International Scientific Conference,European Applied Sciences: modern approaches in scientific researches, Stuttgart, (2013), 155-158.

[3] M.S.Azhenov, D.E.Beisenov, Social stratification in the Republic of Kazakhstan, Almaty, (1999), 140 (in Russian).

[4] A. Kaufman, Introduction a combinatorique en vue des applications, DUNOD, Paris, (1968).

[5] V.C. Ageev, Intergroup interaction: social and psychological problems, $M S U$, (1990), 180 (in Russian).

[6] N.T.Rustamov, B.B.Ibragimov, K.E.Batyrkhan, Modeling stratification of socio-economic systems, Herald IKTU A. Yasawi, 2, (2012), 58-63 (in Russian).

[7] N.T.Rustamov, Graph - model of social stratification, Herald IKTU A. Yasawi, 1(81), (2013), 8-16 (in Russian). 
